\title{
Oral submucous fibrosis-a case report
}

\begin{abstract}
Oral sub mucous fibrosis (OSMF) is a chronic, insidious, disabling disease of oral mucosa, oropharynx, and rarely, the larynx affecting millions of people worldwide with a prevalence rate of $0.4 \%$ in Indian rural population. It results in difficulty to open the mouth and can be disabling to the patient. The awareness of such a condition among oral physicians can help in timely diagnosis and thus appropriate treatment can be administered depending on the degree of involvement. Patients with OSMF need treatment for trismus correction, reconstructive surgery for any simultaneous oral malignancy. A case of oral sub mucous fibrosis occurring in a 35 year old male patient is presented with emphasis on the review of literature.
\end{abstract}

Volume 2 Issue I - 2017

\section{Asha ML,Aprajita Dua, Lekshmy J, Basetty Neelakantam Rajarathnam, Mahesh Kumar HM, Ankita Gupta \\ Department of Oral Medicine and Radiology, Syamala Reddy Dental College, India} Correspondence: Aprajita Dua, Department of Oral Medicine
and Radiology, Syamala Reddy Dental College, \#I I I/I, SGR
College Main Road Munnekolala, Marathahalli (Post), Bangalore-
560037, India, Tel 09972458292, Email apradua@gmail.com

Received: January 30, 2017 | Published: February 03, 2017

\section{Introduction}

Oral submucous fibrosis (OSMF) is a potentially malignant disorder caused by chewing of betel quid. It results in progressive inability to open the mouth. ${ }^{1,2}$ Ram Nathan has recommended that OSMF may be a mucosal change that may be secondary to chronic iron deficiency calling it as an Asian analogue of sideropenic dysphagia. ${ }^{3}$ OSMF has been predominantly reported among Indians living in India as well as outside, to a lesser extent among other Asiatics and, sporadically, among Europeans. With a reported prevalence ranging up to $0.4 \%$ in Indian rural populations, ${ }^{4}$ several million individuals are estimated to suffer from this malady. It has a malignant transformation rates as high as $7.6 \%{ }^{5-7}$ and a relative risk of 397.3 for oral cancer development compared to individuals with tobacco habits but without any precancerous lesion or condition. ${ }^{7}$ The present case report describes a case of OSMF in a 35 year old male patient.

\section{Case report}

A 35years, old male patient (Figure 1) reported to the department of oral medicine and radiology with the chief complaint of inability to open mouth since 8-9 months. Patient gave a history of burning senstation on having spicy food. (Visual Analogue Score of $6 \mathrm{~mm}$ ). History of khaini chewing since 10 years with a frequency of 10-11times/day was present. No gross asymmetry detected. Patient had sunken cheeks with reduced cheek blowing capacity (Figure 2 ) and tongue protrusion and restricted mouth opening (Figure 3). Inspectory findings revealed pale blanched appearance of right buccal mucosa extending from the retrocommisural area up to the retro molar area anterior posteriorly and superior inferiorly from approximately 5 $\mathrm{mm}$ above and below the line of occlusion. Marble stone appearance of mucosa was seen Figure 4. Pale blanched appearance of soft palate, faucial pillars was also observed. Bud shaped uvula was present (Figure 5). On palpation interincisal opening was limited to $19 \mathrm{~mm}$. Vertical bands were palpable in the buccal mucosa with respect to right posterior molar region on right side and the retro molar area. Circular band were palpable with respect to the mandibular labial mucosa. Based on the clinical findings a provisional diagnosis of Oral Sub mucous Fibrosis Stage III $^{8}$ was made. Incisional biopsy was taken and microscopic findings (Figure 6) revealed a stratified squamous parakeratotic epithelium which was atrophied in certain areas with loss of rete ridges. The underlying connective tissue revealed dense bundles of collagen fibres merging with the muscle layer in the deeper connective tissue. Diffuse mild inflammatory infiltrate was seen. The histopathologic features were suggestive of Moderately Advanced Oral Sub mucous Fibrosis ${ }^{8}$ On the basis of Histopathological findings a final diagnosis of Group III (moderately advanced) Oral Sub mucous Fibrosis ${ }^{8}$ was made. Patient counseling was done, advised to quit the habit and Capsule of S.M. Fibro was prescribed once daily for 3 months and patient was on follow up for 3 months (Figure 7). The VAS score for burning sensation was reduced to $1 \mathrm{~mm}$ and there was resolution of the lesion and reduction in palpable bands. Interincisal opening recorded was $30 \mathrm{~mm}$

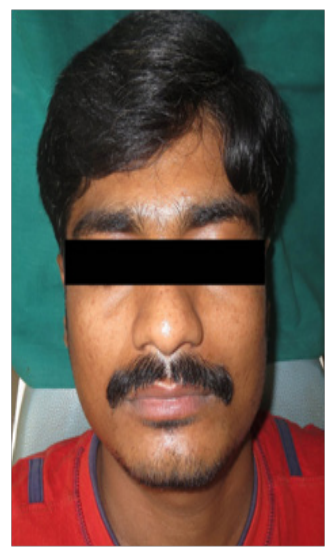

Figure I Extra oral picture of patient aged 35 years old.

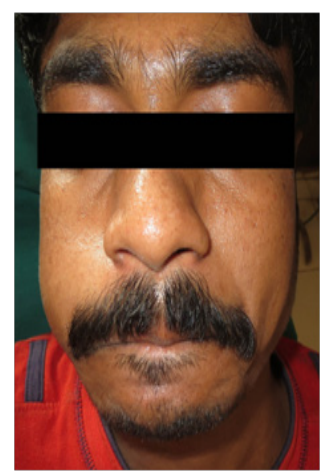

Figure 2 Reduced cheek blowing capacity both right and left side 


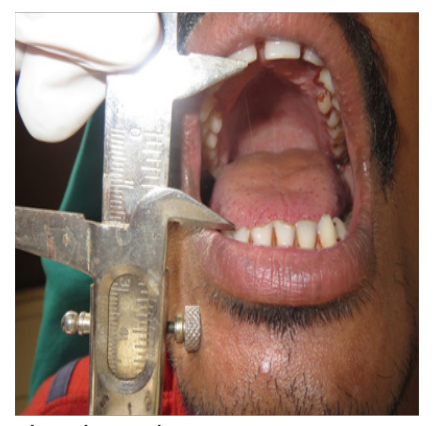

Figure 3 Showing reduced mouth opening.

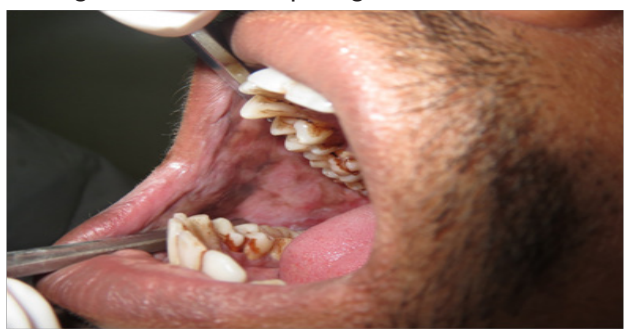

Figure 4 Showing the pale blanched buccal mucosa with respect to the right side

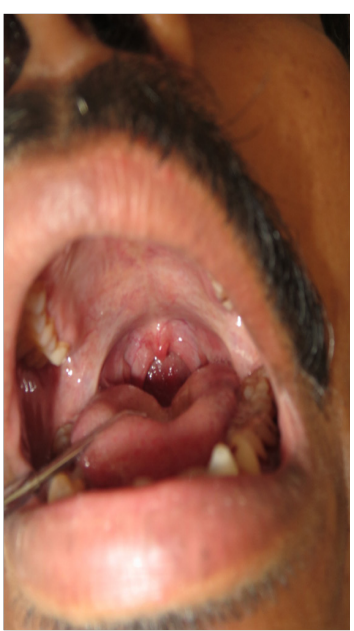

Figure 5: Bud shaped uvula.

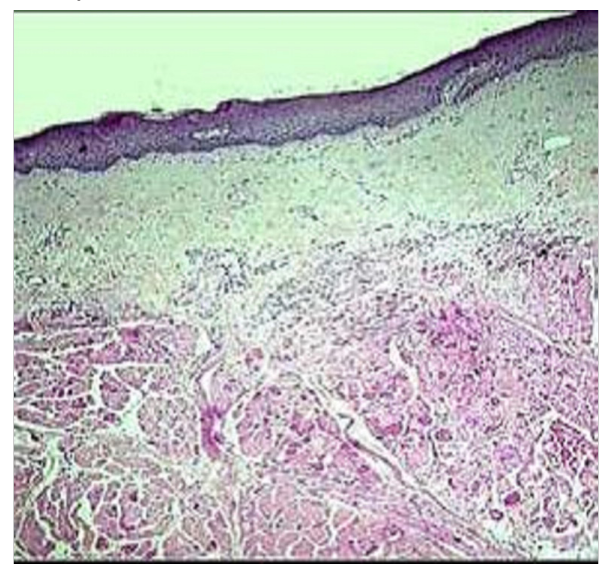

Figure 6: Photomicrograph showing atrophic surface epithelium with absence of rete ridges and sub epithelial hyalinization. Deeper sections show dense collagen fibres and degenerated muscle bundles

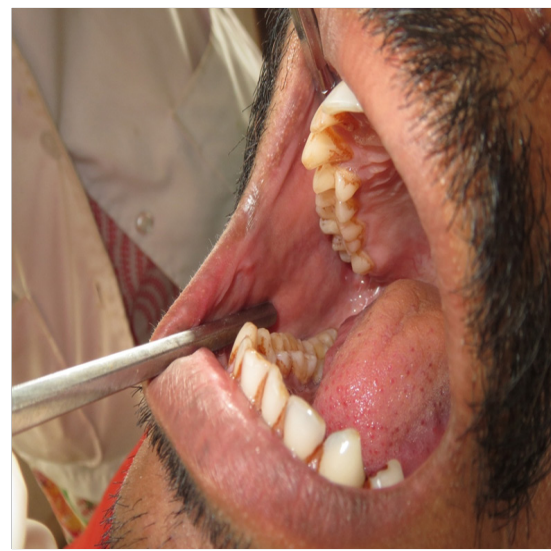

Figure 7: Follow up picture 3 months later.

\section{Discussion}

Oral Sub mucous Fibrosis was first described by SCHWARTZ ${ }^{9}$ in 1952 among five East African women of Indian origin. This was followed by the first description of this condition in India in 1953 in quick succession. ${ }^{10,11}$ Areca nut chewing, smoking tobacco and hypersensitivity to chilies are the causative agents in genetically predisposed patients. ${ }^{12}$ In Central and Southeast Asia, the use of smokeless form of tobacco widely involves the chewing of betel quid or pan-supari. It is a combination of Areca nut, betel leaf, tobacco and slaked lime. This mixture is held closest to the buccal mucosa and slowly chewed over a long period of time. It produces effects similar to smoking tobacco and is addictive. ${ }^{13}$ OSMF affects mostly the buccal mucosa, lips, retro molar areas, soft palate. ${ }^{12}$ It is a chronic condition characterized by mucosal rigidity of varying intensity due to fibro-elastic transformation of the juxta-epithelial layer. This leads to restricted oral opening; when the tongue is involved, its protrusion may be impaired. ${ }^{4}$ Early lesion present as a blanching of buccal mucosa, imparting a marble-like appearance but later lesions reveal palpable fibrous bands rendering the mucosa pale, thick and stiff. This leads to progressive inability to open the mouth, burning sensation, pain, dysphagia and finally hearing loss. ${ }^{12}$

Most affected individuals report a burning sensation of the oral mucosa aggravated by spicy food. The presence of palpable fibrous bands is a requisite diagnostic criterion for this condition, as otherwise other mucosal conditions such as anemic states are likely to be diagnosed as OSMF, especially in field studies. ${ }^{4}$ Sirsat and Khanolkar investigated the outcome of capsaicin, which is a component of chili peppers, on the palate of wister rats and found a limited connective tissue response, but this was increased when the animals were vitamin B12 deficient. Iron and vitamin B12 deficiency has been associated particularly in conjunction with other factors..$^{14}$ In 1919 Paterson and Brown- Kelly described the condition of chronic dysphagia and mucosal atrophy in women with chronic anemia termed as sideropenic anemia or Brown- Kelly- Paterson Syndrome and has the possibility for cancerous change in the oropharynx..$^{15}$ All the accessible treatments only provide symptomatic relief that is short lived. ${ }^{12}$ There is a need for careful observation and follow up in every case in order to retard the disease process. The treatment of OSMF depends on the degree of involvement and timely diagnosis. Patients with OSMF need treatment for trismus correction, reconstructive surgery for any simultaneous oral malignancy. ${ }^{14}$ 


\section{Conclusion}

OSMF is a potentially malignant disorder, which requires close monitoring and follows up. Areca nut has been imposed as one of the initiating factors for the disease causation. Various treatment modalities are present and are used as per the stage of disease. This case report deals with the presentation of the condition in a 35 year old male patient with a chronic habit of arecanut. Early diagnosis and emphasis on patient counseling especially in a youth along with the appropriate treatment can help improve the condition drastically.

\section{Acknowledgements}

None.

\section{Conflict of interest}

The author declares no conflict of interest.

\section{References}

1. Stone DJ, Gal TJ. Airway management. In: Miller RD editor. Anesthesia 5th ed. USA: Springer; 2000. p. 1414-1451.

2. Mahajan R, Jain K, Batra YK. Submucous fibrosis secondary to chewing of quids: another cause of unanticipated difficult intubation. Can J Anaesth. 2002;49(3):309-311.

3. Practice guidelines for management of the difficult airway: a report by the asa task force on management of the difficult airway. Anesthesiology. 1993;78:597-602.

4. Pindborg JJ, Mehta FS, Gupta PC, et al. Prevalence of oral submucous Fibrosis among 50,915 indian villagers. Br J Cancer. 1968;22(4):646654.
5. Pindborg JJ, Murti PR, Bhonsle RB, et al. Oral submucous fibrosis as a precancerous condition. Scand J Dent Res. 1984;92(3):224-229.

6. Murti PR, Bhonsle RB, Pindborg JJ, et al. Malignant transformation rate in oral submucous fibrosis over a 17-year period. Community Dent Oral Epidemiol. 1985;13(6):340-341.

7. Gupta PC, Bhonsle RB, Murti PR, et al. An epidemiologic assessment of cancer risk in oral precancerous lesions in India with special reference to nodular leukoplakia. Cancer. 1989;63(11):2247-2252.

8. More CB, Gupta S, Joshi J, et al. Classification system for oral submucous fibrosis. J Indian Acad Oral Med Radiol. 2012;24(1):24-29.

9. Schwartz J. Atrophiaidiopathica (tropica) mucosae oris. Demonstrated at the $11^{\text {th }}$ international dental congress, England: Springer; 1952.

10. Lal D. Diffuse oral submucous fibrosis. J All India Dent Assoc. 1953;26:1-3.

11. JosHi SG. Submucous fibrosis of the palate and the pillars. Indian $J$ Otolaryngol. 1953;4:14.

12. Cox SC, Walker DM. Oral submucous fibrosis: a review. Aust Dent J. 1996;41(5):294-299.

13. Cormack RS, Lehane J. Difficult tracheal intubation in obstetrics. Anaesthesia. 1984;39(11):1105-1111.

14. Shah B, Lewis MAO, Bedi R. Oral Submucous fibrosis in an 11-year-old bangladeshi girl living in the united kingdom. $\mathrm{Br}$ Dent $\mathrm{J}$. 2001;191:130-132.

15. Merchant AT, Haider SM, Firkee FF. Increased severity of oral submucous fibrosis in young Pakistani men. Br J Oral Maxillofacial Surg. 1997;35:284-287. 